\title{
ANALISIS PENGUASAAN KONSEP AWAL FISIKA PADA PEMBELAJARAN MENGGUNAKAN MODEL ADVANCE ORGANIZER BERBASIS EKSPERIMEN TERHADAP HASIL BELAJAR FISIKA
}

\author{
Ramlan Sungkawan dan Motlan \\ Jurusan Pendidikan Fisika-Program Pascasarjana Universitas Negeri Medan \\ sungkawanramlan@ rocketmail.com
}

\begin{abstract}
Abstrak. Penelitian ini bertujuan untuk mengetahui perbedaan: (1) hasil belajar Fisika siswa dengan penerapan model pembelajaran Advance Organizer Berbasis Eksperimen dan model pembelajaran Direct Instruction. (2) hasil belajar Fisika siswa yang memiliki penguasaan konsep awal rendah dan penguasaan konsep awal tinggi. (3) Interaksi antara model pembelajaran Advance Organizer Berbasis Eksperimen dan Direct Instruction dengan tingkat penguasaan konsep awal dalam meningkatkan hasil belajar Fisika. Penelitian ini merupakan penelitian quasi eksperimen dengan populasi dan sampelnya adalah siswa kelas X SMK N 1 Pantai Labu pada semester dua. Instrumen yang digunakan terdiri dari: (1) tes penguasaan konsep awal (2) tes hasil belajar dengan materi pokok listrik dinamis. Adapun tes yang digunakan untuk memperoleh data adalah berbentuk essay. Data dalam penelitian ini dianalisis dengan menggunakan analisis ANAVA dua jalur. Hasil penelitian menunjukkan bahwa: (1) Terdapat perbedaan hasil belajar Fisika antara siswa yang menggunakan model pembelajaran Advance Organizer Berbasis Eksperimen dibandingkan dengan siswa yang menggunakan model pembelajaran Direct Instruction. (2) Terdapat perbedaan hasil belajar Fisika siswa yang memiliki penguasaan konsep awal rendah dan penguasaan konsep awal tinggi baik di kelas Advance Organizer Berbasis Eksperimen dan di kelas Direct Instruction. (3) Tidak terdapat interaksi antara model pembelajaranAdvance Organizer Berbasis Eksperimen dan Direct Instruction dengan tingkat penguasaan konsep awal dalam meningkatkan hasil belajar Fisika.
\end{abstract}

Kata kunci: advance organizer, konsep awal fisika, eksperimen, hasil belajar

\section{THE ANALYSIS OF MASTERY THE BEGINNING CONCEPT OF PHYSIC WITH ADVANCE ORGANIZER LEARNING BASED EXPERIMENT TOWARD STUDENTS' PHYSIC LEARNING ACHIEVEMENT}

\author{
Ramlan Sungkawan dan Motlan \\ Department of Physical Education-Graduate State University of Medan \\ sungkawanramlan@rocketmail.com
}

\begin{abstract}
This study was aimed to determine the differences between: (1) student's study result of using advance organizer Model and direct instruction
\end{abstract}


model and (2) student's study result who at first have low or high comprehension in physical concept. (3) The relation between advance organizer model and direct instruction model to develop student study interest in physics. This is quasi experimental research which students of second semester of grade X SMK N 1 Pantai Labu Deli Serdang as a population chose random sample of each class. The instrument that is used: (1) test for first comprehension of concept (2) test for study result which "Dynamic Power" as a basic material. The test is used to obtain the data is form of essay. And the data were collected in essay and analyzed according to ANAVA. It shows that: (1) there are the different between students' study results that use advance organizer and direct instruction. (2) There are the differences between students' study results that have low or high skill in advance organizer or Direct Instruction class. (3) There is no interaction between the using learning of advance organizer or direct Instruction and the degree of concept comprehension to develop students' study result.

\section{Keywords: advance organizer, the first physical concept, exsperiment, study result}

\section{PENDAHULUAN}

Pendidikan merupakan suatu kegiatan yang universal dalam kehidupan manusia. Pendidikan bagi manusia adalah proses, menemukan, menjadi dan mengembangkan diri sendiri dalam keseluruhan dimensi kepribadian. Kegiatan utama dalam proses pendidikan adalah aktivitas siswa belajar. Adapun fungsi pendidikan adalah untuk membimbing anak kearah suatu tujuan yang bernilai tinggi yaitu agar anak tersebut bertambah pengetahuan dan keterampilannya serta memiliki sikap yang benar. Jadi, pendidikan yang baik adalah usaha yang berhasil membawa semua anak didik kepada tujuan yang diharapkan.

Proses pembelajaran Fisika pada saat ini secara umum belum berdampak terhadap kemampuan penguasaan konsep. Pembelajaran Fisika sebagian besar hanya menekankan pada aspek produk seperti menghapal konsepkonsep, prinsip-prinsip atau rumus dan tidak memberikan kesempatan siswa terlibat aktif dalam proses-proses Fisika sehingga tidak dapat menumbuhkan sikap ilmiah siswa. Beberapa penelitian pembelajaran berbasis konstruktivis telah dilakukan untuk melihat efektivitasnya dalam konstruksi pengetahuan oleh siswa sendiri dan menumbuh kembangkan sikap ilmiah. Hal ini dilakukan sesuai pendapat Bruner (Dahar, 2011) bahwa selama kegiatan belajar berlangsung hendaknya siswa dibiarkan mencari atau menemukan sendiri makna segala sesuatu yang dipelajari.

Penguasaan konsep memberikan pengertian bahwa konsep-konsep yang diajarkan kepada siswa bukanlah sekedar bahan hapalan saja, tetapi konsep itu harus dipahami agar dapat digunakan untuk dapat memecahkan masalah yang dihadapi. Penguasaan konsep merupakan tingkatan hasil proses belajar seseorang sehingga dapat mendefenisikan atau menjelaskan suatu bagian informasi dengan kata-kata sendiri, dengan kemampuan siswa menjelaskan atau mendefenisikan berarti siswa tersebut telah memahami konsep atau prinsip dari bahan-bahan pelajaran, meskipun penjelasan yang diberikan susunan kalimatnya tidak sama dengan konsep yang diberikan, tetapi maknanya tidak berbeda. (Dahar, 2011).

Penguasaan konsep Fisika oleh siswa akan lebih berhasil jika diterapkan model pembelajaran sesuai yang dapat membuat siswa mencari, menyelesaikan masalah dan memahami Fisika itu sendiri sehingga siswa dapat 
membangun konsep-konsep Fisika atas dasar nalarnya sendiri yang kemudian dikembangkan atau mungkin diperbaiki oleh guru yang mengajar. Salah satu model yang cocok untuk pembelajaran yang bertujuan agar siswa dapat mengusai konsep Fisika adalah dengan menggunakan model Advance Organizer berbasis eksperimen.

Olio dan Tony (2007) mengemukakan bahwa model pembelajaran Advance Organizer dapat membantu para siswa mengorganisir informasi yang diperoleh untuk menguatkan struktur kognitif siswa ketika mempelajari konsep-konsep atau informasi yang baru dan bagaimana sebaiknya pengetahuan itu disusun serta dipahami dengan benar.

Melalui model pembelajaran Advance Organizer siswa diharapkan dapat membangun pengetahuan dan pemahamannya sendiri tentang fakta dan konsep-konsep Fisika dengan cara merekonstruksi sendiri makna melalui pemahaman relevan pribadinya, sehingga siswa dapat mencari, menggunakan, mengingat dan memahami lebih lama konsep Fisika tersebut, dan pembelajaran yang terlaksana lebih bermakna. Dan model ini memfasilitasi tumbuhnya minat siswa dalam memperkuat struktur kogintif. Agar pemahaman siswa dapat lebih muncul maka pada pembelajaran dibantu dengan menggunakan metode yang mendukung hal tersebut, yaitu metode eksperimen. Metode eksperimen pada pembelajaran Fisika dapat mengembangkan keterampilan siswa di mana siswa dapat terlibat aktif dalam penemuan informasi dalam memahami konsep dan dapat bersikap secara ilmiah sehingga motivasi siswa dalam pembelajaran dapat meningkat.

Metode eksperimen pada pembelajaran Fisika dapat mengembangkan keterampilan siswa, siswa dapat melaksanakan praktikum sesuai dengan materi yang sedang dipelajari, karena guru sudah merancang praktikum yang akan dilaksanakan. Siswa tinggal mengikuti langkah-langkah praktikum yang terdapat di LKS. Hal ini sesuai dengan hakekat Fisika yaitu siswa harus terlibat dalam penemuan informasi dan prinsip serta dapat bersikap secara ilmiah seperti sikap fisikawan dan ilmuan IPA.

\section{MODEL PEMBELAJARAN ADVANCE ORGANIZER}

Model pembelajaran advance organizer merupakan salah satu model pembelajaran dari rumpun pemprosesan informasi, sehingga dapat digunakan dalam pembelajaran untuk memahami konsep dalam Fisika karena model pembelajaran advance organizer cocok untuk menyajikan fakta, keterampilan, konsep dan prinsip-prinsip yang didasarkan pada tujuan kognitif pada tingkat pengetahuan dan pemahaman.

Model pembelajaran advance organizer merupakan suatu cara belajar untuk memperoleh pengetahuan baru yang dikaitkan dengan pengetahuan yang ada pada pembelajaran, artinya setiap pengetahuan mempunyai struktur konsep tertentu yang membentuk kerangka dari sistem pemprosesan informasi yang dikembangkan dalam pengetahuan. Menurut Ausubel (Joyce, 2009) Advance organizer menyediakan konsep-konsep dan prinsip-prinsip pada siswa secara langsung.

Ausubel (Arends, 2008) juga mengemukakan bahwa melihat kegunaan advance organizer sebagai sarana untuk membantu membuat informasi bermakna bagi siswa. Guru menggunakan advance organizer untuk membantu membuat informasi lebih bermakna bagi siswa dengan menghubungkan pengetahuan sebelumnya dengan pelajaran baru yang diberikannya.

Menurut Joyce (2009) model pembelajaran advance organizer bertujuan memperkuat struktur kognitif dan meningkatkan daya ingat dalam memperoleh informasi baru. Ausubel juga menjelaskan advance organizer sebagai materi pengenalan yang disajikan pertama kali dalam tugas pembelajaran dan dalam tingkat abstraksi yang lebih tinggi dari pada tugas pembelajaran itu sendiri. Tujuannya adalah menjelaskan, mengintegrasikan, dan menghubungkan materi baru dalam tugas pembelajaran dengan materi yang telah dipelajari sebelumnya 
dan juga membantu pembelajar membedakan materi baru dari materi yang telah dipelajari sebelumnya. Pengorganisasian yang paling efektif adalah dengan menggunakan konsepkonsep, ketentuan-ketentuan, dan proposisi yang sudah dikenal sebelumnya oleh siswa. Pengorganisasian memperlihatkan gambaran dari isi materi yang harus disampaikan berupa konsep, proposisi, generalisasi, prinsip, dan hukum-hukum yang terdapat dalam kajian bidang studi.

Ada dua dampak intruksional yang dapat diharapkan dari model ini, yaitu terbentuknya struktur konseptual dan terbentuknya hubungan yang bermakna (meaningfull) antara informasi
Jurnal Pendidikan Fisika

p-ISSN 2252-732X

e-ISSN 2301-7651

dan ide. Menurut Joyce (2009) dampak pengiring model advance organizer ini adalah tumbuhnya minat berinkuri dan siap untuk berpikir kritis dan tepat.

Kunci utama keberhasilan model Advance Organizer ini terletak pada adanya perorganisasian yang baik dalam materi yang diajarkan. Materi yang terorganisasikan dengan baik itu antara lain ditandai oleh adanya hubungan yang terintegrasi dan tepat antara kerangka utama (organizer) dengan isi materi yang diajarkan. Adapun sintaks model pembelajaran Advance Organizer ditunjukkan pada Tabel 1.

Tabel 1. Sintaks Model Pembelajaran Advance Organizer

\begin{tabular}{|l|}
\hline Fase Pertama: \\
Penyampaian/Presentasi Advance Organizer \\
\hline Menjelaskan tujuan pelajaran \\
Menyampaikan organizer \\
Mengidentifikasi definisi ciri-ciri tertentu \\
Memberikan contoh \\
Mengulang \\
Mendorong kesadaran pengetahuan dan pengalaman siswa. \\
\hline Fase Kedua: \\
Penyampaian/Presentasi tugas atau materi pembelajaran \\
\hline Menyajikan materi \\
Mempertahankan perhatian \\
Memperjelas pengolahan menjadi pembelajaran yang \\
masuk akal. \\
Memperjelas aturan materi. \\
\hline Fase ketiga: \\
Memperkuat Pengolahan Kognitif \\
\hline Memperkuat struktur kognitif \\
Memperluas materi pelajaran \\
Menghubungkan informasi baru ke Advance Organizer \\
Mengklarifikasi
\end{tabular}

(Sumber: Joyce, 2009:289)

Lebih lanjut Ausubel menjelaskan bahwa advance organizer dapat memberikan 3 macam manfaat, yaitu: (Uno, 2006).

a. Menyediakan suatu kerangka konseptual untuk materi belajar yang akan dipelajari oleh siswa. b. Berfungsi sebagai jembatan yang menghubungkan antara apa yang sedang dipelajari siswa saat ini dengan apa yang akan dipelajari siswa.

c. Membantu siswa untuk memahami bahan belajar secara lebih mudah. 
Penggunaan pengorganisasian awal (advancee organizer) merupakan suatu alat pengajaran yang direkomendasikan oleh Ausubel untuk mengaitkan bahan-bahan pelajaran baru dengan pengetahuan awal. Pengetahuan awal menggarisbawahi ide-ide utama dalam suatu situasi pembelajaran yang baru dan mengaitkan ide-ide baru tersebut dengan pengetahuan yang telah ada pada pembelajaran.

\section{METODE PENELITIAN}

Penelitian ini akan dilaksanakan pada Semester II Kelas X di SMK Negeri 1 Pantai Labu yang beralamat Jalan Baru Desa Durian Deli Serdang Tahun Ajaran 2012/2013. Penelitian ini akan dilaksanakan pada bulan Juni 2013. Seluruh siswa kelas $X$ semester genap SMK Negeri 1 Pantai Labu T.A. 2012/2013 yang berjumlah 6 kelas dengan 38 siswa per kelas, sehingga seluruh populasi adalah 204 orang.

Penelitian ini termasuk jenis penelitian quasi eksperimen, yaitu merupakan penelitian yang bertujuan untuk mengetahui akibat dari "sesuatu" yang dikenakan pada "subyek" yaitu siswa. Penelitian ini melibatkan dua kelas sampel yang diberi perlakuan yang berbeda. Pada kelas eksperimen dengan model pembelajaran Advance Organizerberbasis eksperimensedangkan kelas kontrol dengan model pembelajaran Direct Instruction. Desain penelitiannya berupa Two Group Pretes-Postes Design.

Tabel 1. Rancangan Desain Penelitian

\begin{tabular}{|l|c|c|c|}
\hline \multicolumn{1}{|c|}{ Sampel } & Pretes & Perlakuan & Postes \\
\hline Kelas Eksperimen & $\mathrm{T}_{1}$ & $\mathrm{X}$ & $\mathrm{T}_{2}$ \\
\hline Kelas control & $\mathrm{T}_{1}$ & $\mathrm{Y}$ & $\mathrm{T}_{2}$ \\
\hline
\end{tabular}

Keterangan:

$\mathrm{T}_{1}:$ Pre test $\quad \mathrm{T}_{2}:$ Post test

$\mathrm{X}$ : Perlakuan (treatment) untuk model pembe-

lajaran Advance Organizerberbasis eksperimen

Y : Perlakuan (treatment) untuk model pembelajaran Direct Instruction

Untuk menguji hipotesis penelitian digunakan teknik analisis data dengan menggunakan Analisis Varians (ANAVA) dua jalur pada taraf siginifikan $\alpha=0,05$ menggunakan uji General Linear Model (GLM) univariat dengan SPSS 17.

a. $H_{O}: \mu_{e}=\mu_{k}$ :

Tidak terdapat perbedaan hasil belajar Fisika siswa dengan model pembelajaran Advance Organizer berbasis eksperimen dan Direct Instruction.

$$
H_{a}: \mu_{e} \neq \mu_{k}:
$$

Terdapat perbedaan hasil belajar Fisika siswa dengan model pembelajaran Advance Organizer berbasis eksperimen dan Direct instruction.

b. $H_{O}: \mu_{R}=\mu_{T}$ :

Tidak terdapat perbedaan hasil belajar Fisika siswa yang memiliki penguasaan konsep awal rendah dan penguasaan konsep awal tinggi.

$$
H_{a}: \mu_{R} \neq \mu_{T}:
$$

Terdapat perbedaan hasil belajar Fisika siswa yang memiliki penguasaan konsep awal rendah dan penguasaan konsep awal tinggi.

c. $A><B=0$ :

Tidak terdapat interaksi antara model pembelajaran Advance Organizer berbasis eksperimen dan Direct Instruction dengan penguasaan konsep awal untuk meningkatkan hasil belajar Fisika.

$$
A><B \neq 0 \text { : }
$$

Terdapat interaksi antara model pembelajaran Advance Organizer berbasis eksperimen dan Direct Instruction dengan penguasaan konsep awal untuk meningkatkan hasil belajar Fisika.

\section{HASIL PENELITIAN DAN PEMBAHASAN}

Terdapat perbedaan hasil belajar Fisika siswa dengan model pembelajaran Advance Organizer berbasis eksperimen dan Direct Instruction

Model pembelajaran Advance Organizer berbasis eksperimen dan model pembelajaran Direct Instruction pada dasarnya memberikan kesempatan bagi siswa sesuai dengan kemampuan yang dimilikinya untuk memperdalam pemahaman tentang konsep-konsep dasar yang dimiliki, khususnya yang berkaitan dengan materi pokok bahasan yang dipelajari siswa, baik melalui guru maupun melalui belajar 
mandiri. Pembelajaran Advance Organizer berbasis eksperimen maupun pembelajaran Direct Instruction adalah salah satu bentuk pembelajaran yang terprogram dan pengajaran yang terprogram merupakan salah satu pengajaran individu yang merujuk pada satu siasat untu mengatur proses pengajaran sedemikian rupa sehingga setiap siswa memperoleh hasil belajar yang optimal. Terbukti dari temuan penelitian yang menguatkan adanya perbedaan yang signifikan dari kedua model pembelajaran tersebut.

Hasil temuan dalam penelitian ini membuktikan bahwa rata-rata hitung hasil belajar Fisika kelas Direct Instruction adalah 77,67 lebih rendah dibandingkan rata-rata hasil belajar Fisika kelas Advance Organizer berbasis eksperimen adalah 83,05. Hal ini dapat dipahami bahwa hasil belajar Fisika kelas Advance Organizer berbasis eksperimen lebih tinggi dari pada kelas Direct Instruction. Penelitian ini sejalan dengan penelitian Yuliani (2007) diperoleh nilai rata-rata pretes 31,00 setelah diberi perlakuan yaitu dengan model pembelajaran Advance Organizer berbasis eksperimen maka hasil belajar siswa meningkat dengan nilai rata-rata 80,40 , dengan judul Pengaruh Model Pembelajaran Advance Organizer berbasis eksperimen Terhadap Hasil Belajar Siswa Pada Materi Pokok Hukum Newton Kelas VIII di SMP Negeri 6 Medan T.P. 2009/2010.

Selanjutnya dengan model pembelajaran Direct Instruction, siswa kurang berkomunikasi antar sesama teman, sedangkan siswa yang di ajar dengan model pembelajaran Advance Organizer berbasis eksperimen, siswa akan lebih bebas mengkomunikasikan temuan yang diperolehnya dengan kelompoknya pada saat melakukan kegiatan belajar. Komunikasi antar teman memberikan solusi yang cepat bagi siswa untuk melengkapi ketidaktahuannya tentang materi pokok yang dipelajari.

Terdapat perbedaan hasil belajar Fisika siswa yang memiliki penguasaan konsep awal rendah dan penguasaan konsep awal tinggi.
Jurnal Pendidikan Fisika

ISSN 2301-7651
Penguasaan konsep awal sangat berpengaruh terhadap hasil belajar Fisika siswa. Dengan demikian siswa yang memiliki penguasaan konsep awal rendah cenderung memperoleh nilai yang kurang memuaskan. Sedangkan siswa yang memiliki penguasaan konsep awal tinggi akan selalu berusaha untuk mencapai prestasi sesuai dengan standar yang ditetapkan. Kondisi teruji secara empiris dengan temuan penelitian yang membuktikan bahwa terdapat perbedaan hasil belajar Fisika siswa yang memiliki penguasaan konsep awal rendah dengan kelompok siswa yang memiliki penguasaan konsep awal tinggi.

Hasil temuan dalam penelitian ini membuktikan bahwa rata-rata hitung hasil belajar Fisika kelompok siswa yang memiliki penguasaan konsep awal rendah sebesar 79,75 lebih rendah dibandingkan rata-rata hasil belajar Fisika kelompok siswa yang memiliki penguasaan konsep awal tinggi sebesar 82,88. Hal ini dapat dipahami bahwa siswa yang memiliki penguasaan konsep awal tinggi akan menghasilkan hasil belajar Fisika yang tinggi. Penelitian ini sejalan dengan penelitian Destini (2005) diperoleh nilai penguasaan konsep awal rendah sebesar 8,80 lebih rendah dibandingkan dengan siswa yang memiliki penguasaan konsep awal tinggi sebesar 13,00, dengan judul: Model pembelajaran Advance Organizer Untuk Meningkatkan Penguasaan Konsep Pembiasan Cahaya Dan Keterampilan Generik Siswa SMP.

Jika dilihat dari tingkat kognitifnya, untuk C2, C3 dan C5 hasil belajar dengan penguasaan konsep awal tinggi pada model pembelajaran Advance Organizer berbasis eksperimen yang paling dominan, sedangkan untuk $\mathrm{C} 1, \mathrm{C} 4$, dan C5 hasil belajar dengan penguasaan konsep awal tinggi paling dominan tetapi tidak terlalu jauh perbedaannya dengan hasil belajar dengan penguasaan konsep awal rendah. Hal ini dapat disimpulkan bahwa penguasaan konsep awal tinggi akan menghasilkan hasil belajar yang tinggi.

Jika dilihat dari tingkat kognitifnya, untuk $\mathrm{C} 1, \mathrm{C} 2, \mathrm{C} 3$, dan $\mathrm{C} 4$ hasil belajar dengan penguasaan konsep awal tinggi pada model 
pembelajaran Direct Instruction yang paling dominan, sedangkan untuk C5, dan C6 hasil belajar dengan penguasaan konsep awal rendah dan tinggi hampir sama.

\section{Interaksi Antara Model Pembelajaran} Advance Organizer berbasis eksperimen Dan Direct Instruction Dengan Penguasaan Konsep Awal Siswa Untuk Meningkatkan Hasil Belajar

Berdasarkan output ANOVA diperoleh $F_{\text {hitung }}$ untuk interaksi (Model Pembelajaran* Penguasaan Konsep Awal) lebih kecil dari $\mathrm{F}_{\text {tabel }}$ $(0,58<4,02)$ atau jika dilihat dari nilai signifikannya diperoleh $\alpha=0,05<\operatorname{sig} 0,45$. Karena itu hipotesis ketiga dalam penelitian ini ditolak yaitu tidak ada interaksi antara model pembelajaran Advance Organizer berbasis eksperimen dan Direct Instruction dengan penguasaan konsep awal siswa terhadap hasil belajar Fisika siswa. Penelitian ini sejalan dengan penelitian Destini (2005) diperoleh nilai sig $0,05<0,10$, artinya tidak ada interaksi antara model pembelajaran Advance Organizer dengan penguasaan konsep (rendah, sedang dan tinggi).
Gambar 1 di bawah ini memperlihatkan tidak adanya interaksi antara model pembelajaran dengan penguasaan konsep awal siswa.

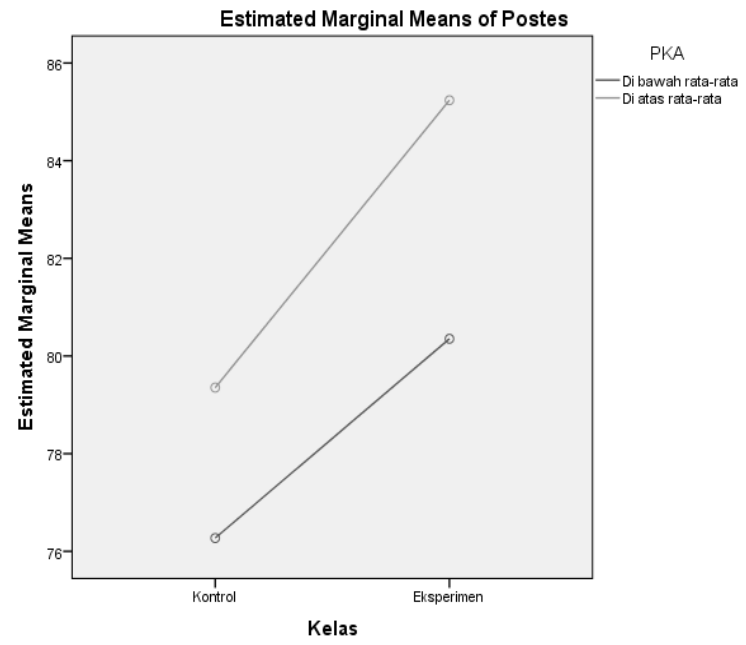

Gambar 1. Grafik Interaksi Antara Model Pembelajaran Dengan Penguasaan Konsep Awal Siswa

Dalam menganalisis perbedaan antar kelompok maka digunakan analisis Post Hoc Test dengan uji Schefee. Hasil yang diperoleh disajikan dalam Tabel 2.

Dependent Variable: Postes

Tabel 2. Multiple Comparisons

Schaeffer

\begin{tabular}{|c|c|c|c|c|c|c|}
\hline \multirow[t]{2}{*}{ (I) Interaksi } & \multirow[t]{2}{*}{ (J) Interaksi } & \multirow{2}{*}{$\begin{array}{c}\text { Mean } \\
\text { Difference (I- } \\
\text { J) }\end{array}$} & \multirow[t]{2}{*}{ Std. Error } & \multirow[t]{2}{*}{ Sig. } & \multicolumn{2}{|c|}{$95 \%$ Confidence Interval } \\
\hline & & & & & $\begin{array}{l}\text { Lower } \\
\text { Bound }\end{array}$ & $\begin{array}{l}\text { Upper } \\
\text { Bound }\end{array}$ \\
\hline \multirow{3}{*}{$\begin{array}{l}\text { Kontrol PKA } \\
\text { Dibawah rata- } \\
\text { rata }\end{array}$} & Kontrol PKA Diatas rata-rata & $-3,08$ & 2,09 & 0,54 & $-9,09$ & 2,93 \\
\hline & Eksperimen PKA dibawah rata-rata & $-4,08$ & 2,09 & 0,29 & $-10,09$ & 1,93 \\
\hline & Eksperimen PKA diatas rata-rata & $-8,97^{*}$ & 1,98 & 0,00 & $-14,64$ & $-3,29$ \\
\hline \multirow{3}{*}{$\begin{array}{l}\text { Kontrol PKA } \\
\text { Diatas rata-rata }\end{array}$} & Kontrol PKA Dibawah rata-rata & 3,08 & 2,09 & 0,54 & $-2,93$ & 9,09 \\
\hline & Eksperimen PKA dibawah rata-rata & $-1,00$ & 2,23 & 0,98 & $-7,38$ & 5,38 \\
\hline & Eksperimen PKA diatas rata-rata & $-5,89$ & 2,12 & 0,06 & $-11,95$ & 0,18 \\
\hline \multirow{3}{*}{$\begin{array}{l}\text { Eksperimen PKA } \\
\text { dibawah rata-rata }\end{array}$} & Kontrol PKA Dibawah rata-rata & 4,08 & 2,09 & 0,29 & $-1,93$ & 10,09 \\
\hline & Kontrol PKA Diatas rata-rata & 1,00 & 2,23 & 0,98 & $-5,38$ & 7,38 \\
\hline & Eksperimen PKA diatas rata-rata & $-4,89$ & 2,12 & 0,16 & $-10,95$ & 1,18 \\
\hline \multirow{3}{*}{$\begin{array}{l}\text { Eksperimen PKA } \\
\text { diatas rata-rata }\end{array}$} & Kontrol PKA Dibawah rata-rata & $8,97^{*}$ & 1,98 & 0,00 & 3,29 & 14,64 \\
\hline & Kontrol PKA Diatas rata-rata & 5,89 & 2,12 & 0,06 &,- 18 & 11,95 \\
\hline & Eksperimen PKA dibawah rata-rata & 4,89 & 2,12 & 0,16 & $-1,18$ & 10,95 \\
\hline
\end{tabular}


Berdasarkan dari hasil analisis data hipotesis ketiga ditolak yaitu tidak adanya interaksi antara model pembelajaran Advance Organizer berbasis eksperimen dan Direct Instruction dengan penguasaan konsep awal siswa dalam meningkatkan hasil belajar Fisika. Artinya model pembelajaran dan penguasaan konsep awal tidak saling mempengaruhi, siswa yang mempunyai penguasaan konsep awal tinggi tanpa model pembelajaran akan memperoleh hasil belajar yang tinggi sebaliknya, siswa yang mempuyai penguasaan konsep awal rendah maka hasil belajarnya rendah.

Temuan hasil penelitian mengungkapkan bahwa kemampuan awal siswa kedua kelompok sampel tidak berbeda secara signifikan sebelum materi diajarkan. Setelah materi diajarkan yaitu untuk siswa kelas eksperimen dengan menggunakan model pembelajaran advance organizer berbasis eksperimen dan untuk siswa kelas kontrol dengan menggunakan model pembelajaran direct instruction. Hasil penelitian mengungkapkan bahwa hasil belajar siswa yang diajarkan dengan menggunakan model pembelajaran advance organizerberbasis eksperimen cenderung lebih baik dibandingkan dengan siswa yang diajarkan dengan model pembelajaran direct instruction. Hasil penelitian juga mengungkapkan bahwa hasil belajar siswa yang memiliki penguasaan konsep awal tinggi lebih baik daripada siswa yang memiliki penguasaan konsep awal rendah. Selanjutnya hasil pengujian hipotesis membuktikan bahwa tidak terdapat interaksi antara model pembelajaran advance organizerberbasis eksperimen dan penguasaan konsep awal terhadap hasil belajar.

\section{SIMPULAN}

Berdasarkan hasil analisa data dapat disimpulkan:

a. Terdapat perbedaan hasil belajar Fisika antara siswa yang menggunakan model pembelajaran Advance Organizer berbasis eksperimen dibandingkan dengan siswa yang menggunakan model pembelajaran Direct Instruction.

b. Terdapat perbedaan hasil belajar Fisika siswa yang memiliki penguasaan konsep awal rendah dan penguasaan konsep awal tinggi baik di kelas Advance Organizer berbasis eksperimen dan di kelas Direct Instruction.

c. Tidak terdapat interaksi antara model pembelajaran Advance Organizer berbasis eksperimen dan Direct Instruction dengan tingkat penguasaan konsep awal dalam meningkatkan hasil belajar Fisika. Dengan kata lain, siswa yang diberikan model pembelajaran Advance Organizer berbasis eksperimen, penguasaan konsep awalnya selalu baik di setiap kelompok kelas rendah dan tinggi dibandingkan dengan model pembelajaran Direct Instruction.

\section{DAFTAR PUSTAKA}

Arends, R. I. 2008. Learning to Teach (7th ed.). Belajar untuk Mengajar (Terjemahan Helly Prajitno Soetjipto dan Sri Mulyantini Soetjipto pada Tahun 2008). Yogyakarta : Pustaka Pelajar.

Dahar, R.W. 2011. Teori-Teori Belajar dan Pembelajaran. Bandung: Erlangga.

Destini, R. 2005. Pengaruh Strategi Pembelajaran Advance Organizer dan Kreativitas Terhadap Hasil Belajar Fisika SMA Swasta Al Washiliyah Medan. Tesis. Medan: Pustakaan Pascasarjana Unimed.

Joyce, B., Weil, M. \& Calhoun, E. 2009. Models of Teaching ( $8^{\text {th }}$ ed.). Model-Model Pengajaran (Terjemahan Achmad Fawai \& Ateilla Mirza). Yogyakarta: Pustaka Pelajar.

Olio, J.M.D, dan Tony, D. 2007. Models of Teaching. USA: Sage Publications.

Yuliani, Y. 2007. Pembelajaran dengan Model Advance Organizer untuk Meningkatkan Pemahaman Matematis Siswa SMA. Tesis. Bandung: FPS UPI.

Uno, H. 2006. Psikologi Pendidikan. Jakarta: Bumi Aksara. 